\title{
Student Perception And Challenges Facing Academic Advising
}

\author{
Tahmoures A. Afshar, Ph.D., MBA, Woodbury University, USA
}

\begin{abstract}
This study examined the patterns of student perception regarding academic advising in an undergraduate program in a privately operated school. Participants were 156 students enrolled in fall 2004 term and were asked to respond to both a 15 structured question questionnaire and an open-ended questionnaire. In the former format students were asked to rate their current advisor on each question using a scale from 1 to 4 , where I indicated that student was very dissatisfied and 4 indicated that student was very satisfied. Our findings revealed that student's satisfaction varied from question to question. Students were most satisfied with those questions that measured their social and personal needs and the advisor's attitudinal skill. The major source of student's dissatisfaction came from advisor's lack of knowledge and information related to both institutional and non-institutional issues.
\end{abstract}

Keywords: academic advising, student retention, perspective approach, developmental approach, interpersonal skills, information related skills, attitudinal skills

\section{INTRODUCTION}

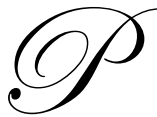

rivate college and universities have always been tuition driven that is dependent upon student enrollment in order to meet budgetary and academic goals. Only recently, however, have these institutions come to realize that there are two sides to the enrollment equation-recruitment and retention. No longer is it enough just to recruit new students but a successful enrollment strategy must include a comprehensive plan for the retention of students.

Several studies have focused on this issue of retention as part of a broader enrollment strategy, especially emphasizing those factors which impact student retention. Tinto $(1975,1987,1993)$ has empirically demonstrated that student retention is affected by the following three categories of variables. The first category reflects student goal commitment, the second category reflects the institutional commitment, and the third reflects financial status. According to his findings the more comfortable the student is in a particular institution or academic environment the greater the likelihood the student will remain at that institution. Mohr et al (1998) found a similar situation. Their analysis suggested that non-retention of seniors be best predicted by dissatisfaction with academic guidance, dissatisfaction with access to school related information, and dissatisfaction with the quality of education as well as by feelings of institutional alienation.

Similarly, numerous studies (Couch 2004,Borland 2001-2002, Creamer 2000,Wilson et al 1997, King 1993,Creeden 1990 and Backhus 1989, among others) have explored the importance of an effective academic advising on student's retention rates. The literature, has defined student-advisor relationship has either perspective or development in approach. Under perspective approach, advisor assists student with registration process, major/minor decision making process. Under the development approach, advisor assists student to develop an educational plan consistent with student's life goals and objectives (Fielstein, 1989, P.33).

In developing an instrument to evaluate advising Cashin (1979) has classified advisor behavior in three categories. The first category included interpersonal skills and good counseling techniques such as inquiry, discussion, and involvement. The second category consisted of limiting behavior such as rushing through appointments. The third category included advisor's information and knowledge of graduation requirements. 
A study by Crockett (1978) indicated four major factors that students expected their advisors to possess. These were a) accessibility, b) specific and accurate information, c) advice and counsel, and d) personal and caring relationship.

A study by Kelly et al (1991) revealed empirically that students evaluated their advisors based on four criteria: a) socio-emotional, b) meeting dynamics, c) knowledge, and d) problems. Lowe et al (2000) examined the academic advising process in a professional school. In their study students were asked to rate the importance of each advisor responsibilities. Overall, twelve responsibilities were considered in their study.

\section{PURPOSE OF STUDY}

Our purpose in this study is to examine the pattern of student perception regarding academic advising as one component in student retention. We would like to know a) whether or not students are satisfied with university's current advising process, b) empirically demonstrate what factors caused their satisfaction and/or their dissatisfaction, and c) whether or not our findings confirmed the previous studies results. Finally, spell out the characteristics of an effective/successful academic advisor, an issue that has not been properly addressed in previous literature.

Within the context of the literature, two advisory components were used in this study. The first component was about student's needs and concerns in an effective academic advising. The second component was about advisor's characteristics. Regarding the first component, we introduced the following categories:

a. Social and personal needs of student, such as those services and caring student expects to receive when contacting advisors, including listening and respecting

b. Information related concerns, such as assisting student to understand institution's general studies guidelines, graduation requirements, and interpretation of university's catalog

c. Life goals and objectives concern, such as assisting student to platform their future career and job

Regarding the second advisory component, i.e., advisor's characteristics and behavior in respond to student's needs and concerns in an effective academic advising process we adopted followings:

a) Interpersonal skills such as being approachable to talk, and being available to students

b) Information related skills such as being familiar with institution's rules, regulation, policies, and procedures

c) Attitudinal skills such as caring, respecting, and understanding

\section{METHOD}

Sample: Participants for this study were 156 students enrolled in a privately operated urban university who completed a two-set questionnaire during Spring Semester 2004. The survey was designed and conducted by the university's counseling Center and results were then shared among all faculties as a public information.

The sample of 156 students represented almost 17 percent of university's undergraduate population. $26 \%$ of participants were freshman, $31 \%$ sophomore, $29 \%$ junior and $14 \%$ Senior.

The first set of questionnaire included 15 structured questions, reflecting advisor's responsibilities through which student's satisfaction/dissatisfaction was measured. In this phase, student was asked to rate their current advisor on each question using a scale from 1 to 4 , where 1 indicated that student was very dissatisfied and 4 indicated that student was very satisfied.

The second questionnaire was designed to learn about student's perception of an effective academic advising using open-ended questions. In this format, student was asked to comment on the following three categories: a) general comments regarding advising and its process, b) what items advisor would share with student, c) what items student was expecting to receive from advisor and d) whether or not advisor met student's expectations. 


\section{RESULTS}

\section{Structured Questions}

We employed 15 structured questions as the basis for our study. Table 1 indicates which one of these questions was used to represent each category of both student as well as advisor's behavioral needs and concern and Table 2 shows the overall results.

Our finding in Table 2, revealed that student's degree of satisfaction measured in percentages, varied widely from one question to another as well as from very dissatisfied to very satisfied category. In very satisfied category, students indicated $78 \%$ preferences for advisors to take the advising process seriously (question \#5). However, students in a satisfied category (19\%) did not prefer this item. The lowest preference rate was $49 \%$ in very satisfied category, which belonged to question \#11. This question was regarding discussing career and internship opportunities (See Table 2). This result was consistent with student's very dissatisfied (dissatisfied) percentage rate, $11 \%(4 \%)$.

Surprisingly, student showed a very highest preference rate (35\%) for question \#11 in the satisfied category. The lowest percentage rate in this category was 15\% that belonged to the question \#7 (Prepares for meetings). However, this question was not rated the lowest or even lower preference rates in the other three choices of satisfaction levels that student had to choose from.

In order to identify which advising activities were more satisfied by student, we rearranged the content of Table 2. As evidenced from Table 2, the most preferred questions in each four categories identified by those that were above average in their own cluster group. In very satisfied (satisfied) category, student rated questions \#2, \#3, $\# 4$, \#5, \#6, \#10, and \#15(\#1, \#6, \#8, \#9, \#10,\#11,\#12, and \#14) as the most satisfactory items. Furthermore, since there was inconsistency between very satisfied and satisfied categories, we combined these two categories and examined their combination instead. Hence, we found that questions\#1, \#2, \#3, \#4, \#5, \#6, \#10, \#14, and \#15 were those questions whose percentage rates were above average in the combined group. Majority of these preferred questions (\#1, \#4, \#5, \#6, and \#15) corresponded with "social and personal needs" of participant students. Remaining questions (\#2, \#3, \#10, and \#14) corresponded with "information related concern" of participant students. In addition, these mostly satisfied advising activities, corresponded best to the "attitudinal skills" of advisors (\#5, \#6,\#10, and \#15), (See Table 1). Thus students were quite satisfied in an academic advising process with "perspective" attribute of their advisors. Our finding confirmed the previous study by Fielstein (1989) where traditional advising approach (perspective) was found to be most preferred by students. Likewise, our finding demonstrated that "interpersonal skills" of advisors did not play a role in bringing satisfaction in academic advising. This result also confirmed Kelly et al study (1991).

As evidenced from Table 2, the most dissatisfied items in very dissatisfied and dissatisfied combined category were questions \#7, \#9, \#11, \#12, \#13, and \#14. The questions \#11and\#13 corresponded to the student's "life goals and objectives concerns". That is, students were quite dissatisfied since their advisor did not address their career objectives adequately. This point was confirmed with the fact that $50 \%$ of those dissatisfied question (\#12, $\# 13$, and \#14) corresponded to "information related skills", and 25\%(\#9and \#11) corresponded to "attitudinal skills" of student advisors. That is, student's major source of dissatisfaction was due to advisor's lack of knowledge and information related to both internal (institutional) and external resources. As can be seen in Table 2, most satisfied questions that were preferred by students were almost the same questions that corresponded with less dissatisfied questions. Similarly, the last satisfied questions were almost identical to most dissatisfied questions. That is there was a consistency in student's response regarding satisfaction and dissatisfaction concern in academic advising process. This result confirmed the finding of Stevenson et al (2006-2007). They noted that student's academic failure was closely related to the poor faculty advisement (p.146).

\section{Open-Ended Questionnaire}

This survey was completed along with 15 structured -question one, simultaneously. The purpose was to encourage students to freely express their feelings on advising. The result of this phase of survey was mixed, while 
some students praised their advisors some of them were not so positive. We summarized their major complains and reasons for their dissatisfaction as well as their complements and satisfaction. This summary provided a basis for our discussion on the characteristics of a successful academic advisor.

a) List of student's major dissatisfactions:

1) Not enough time to discuss schedule and classes on an one to one basis (attitudinal skills)

2) School did not train my advisor enough detail to know which classes I must take for my minor (information related skills)

3) My advisor has very limited time. I am rushed out of the office (interpersonal skills)

4) My advisor did not know what was required for graduation (information related skills)

5) My advisor did not take interest in my future goals (attitudinal skills)

6) My advisor did not take me seriously. I have opinions also and nothing even changes (attitudinal skills)

7) My advisor did not know about GE requirements, almost took two unnecessary classes (information related skills)

8) My advisor was not really open or even listening to me, treated me like I am a high school student (attitudinal skills)

b) List of student's major satisfaction:

1) My advisor helped me to plan for my future courses (attitudinal skills)

2) I felt secure talking to my advisor about my future schedule (attitudinal skills)

3) Always helped me when I needed (interpersonal skills)

4) Listens to my concerns and answers all my questions (interpersonal skills)

5) Helps students with career goals (attitudinal skills)

6) Helps ease my worries with a friendly attitude (attitudinal skills)

7) My advisor is almost always available (interpersonal skill)

8) My advisor shares with me anything I asks (interpersonal skills)

\section{Characteristics Of A Successful/Effective Student Advisor}

Some researchers such as Ryan(1992) have argued that advising is an extension of teaching, hence, an effective advisor may possess all characteristics of an effective teacher. Welty (1989) suggested that advisors should prepare themselves the same manner as they do when attending a regular classroom. Since students identify all effective teachers' characteristics, therefore, student's comments and feelings in this study can be used to determine the characteristics of an effective advisor. Accordingly, student's perception of an effective advisor in this study is as follows: that is, a successful advisor is the one that:

1) should be experienced and well trained by the institution, regarding graduation requirements, general studies and major requirements

2) should act as both a mentor and a friend

3) should be open minded and trustworthy

4) should be career oriented in their field of profession,

5) should prepare for each advising session and should review student file prior to meeting

6) should allocate a longer period

7) should get involved with student personal life as far as a student feels comfortable

8) should assist student to plan for a proper career objective

9) should be familiar with most programs and services that institution offers

10) should be willing to discuss with students out of offered office hours

11) should be resourceful

12) should assist student to choose classes and to determine major/minor

13) should assist student in internship opportunities

14) should inform students about their academic progress as well as their academic problems

Some of these characteristics that students have identified were consistent with finding of this study as far as 15 structured-question format was concerned. As already indicated in the previous part of this study, two major 
classification of advisor's characteristics are information related skills and attitudinal skills. Students were less sensitive to advisor's interpersonal skills.

\section{CONCLUSION}

This study examined the perception of students regarding academic advising in an undergraduate program in a privately operated school. The number of participants in this study was 156 students, which represented almost $18 \%$ of student population. Participant's class level's percentage was freshmen (26\%), sophomore (31\%), juniors $(29 \%)$, and seniors $(14 \%)$.

Our findings revealed that student's degree of satisfaction varied widely from one question to another as well as from very dissatisfied to very satisfied category. Also, there was inconsistency between very satisfied and satisfied as well as dissatisfied and very dissatisfied categories. Hence we combined the results of very satisfied with satisfied categories. We found that majority of preferred questions (those with more than average percentage) corresponded with "social and personal needs" and "information related concerns" of participant students. Students rated their "life goals and objectives concern" in this combined category somewhat less important (less than average). In addition, these mostly satisfied advising activities corresponded with "attitudinal skills" of advisors (more than average). Here, "interpersonal skills" and "information related skills" of advisors were not identified by students as most preferred questions. This may indicate either students were not quite satisfied with these attributes of their advisors or did not assume these characteristics were important. To explore this issue and to maintain consistency we further combined very dissatisfied and dissatisfied categories.

By combining the results of very dissatisfied with dissatisfied categories, we found that student's most dissatisfied items were their "information related concerns" and "life goal and objective concerns" (please refer to Table 1, part 2, and Table 3). These most dissatisfied items corresponded with "information related skill" of academic advisors. Hence, our findings suggested that the major source of student dissatisfaction stemmed from advisor's lack of information related knowledge. This deficiency on advisor's part could be related to information regarding the relevant school or outside and professional resources. Whereas, somewhat less dissatisfied item was "social and personal needs". Surprisingly, students did not identify advisor's "interpersonal skill" as a very dissatisfied or very satisfied item either.

Using open-ended survey, our findings suggested that, when a student was asked to identify a successful (effective) advisor they were more concerned with two major classification of advisor's characteristics: "information related skills" and "attitudinal Skills". However, this study did not suggest that advisor's "interpersonal skills" play any decisive role in their effectiveness. If we could generalize these findings to a general advising situations, our study suggested that an advisor is effective from student's point of view, if could pass on to the students appropriate information as well as if could be able to practice tender loving care and understanding with their advisees. Thus, advisors have an option of changing their behavior patterns and seek help from their institutions for an orderly and timely training regarding various academic guidelines, rules, regulations, and other available monetary and non monetary resources. 
Table 1

\section{Part 1:}

\section{Structured Questions}

1) Refers me to appropriate services when needed

2) Understands General Studies and major requirements

3) Knowledge about academic policies and procedures

4) Approachable and easy to talk with

5) Discusses my academic progress with me

6) Encourages me to make my own decisions

7) Prepares for meetings

8) Available during posted office hours

9) Amount of time available for appointments

10) Understands my point of view

11) Discusses career and internship opportunities

12) Discusses graduation requirements

13) Discusses my education and career goals

14) Helps select courses appropriate for my abilities

15) Takes the advising process seriously

Part 2:

Student Perception

Goals

Questions that was best met the goal

a. Social and personal needs

b. Information related concerns

c. Life goals and objectives
$1,4,5,6,7,8,9,15$

$2,3,10,12,14$

11,13

Part 3:

Advisor Perception

Goals Questions that was best met the goal
a. Interpersonal skills
$4,7,8$
b. Information related skills
c. Attitudinal skills
$1,2,3,12,13,14$
$5,6,9,10,11,15$ 
Table 2

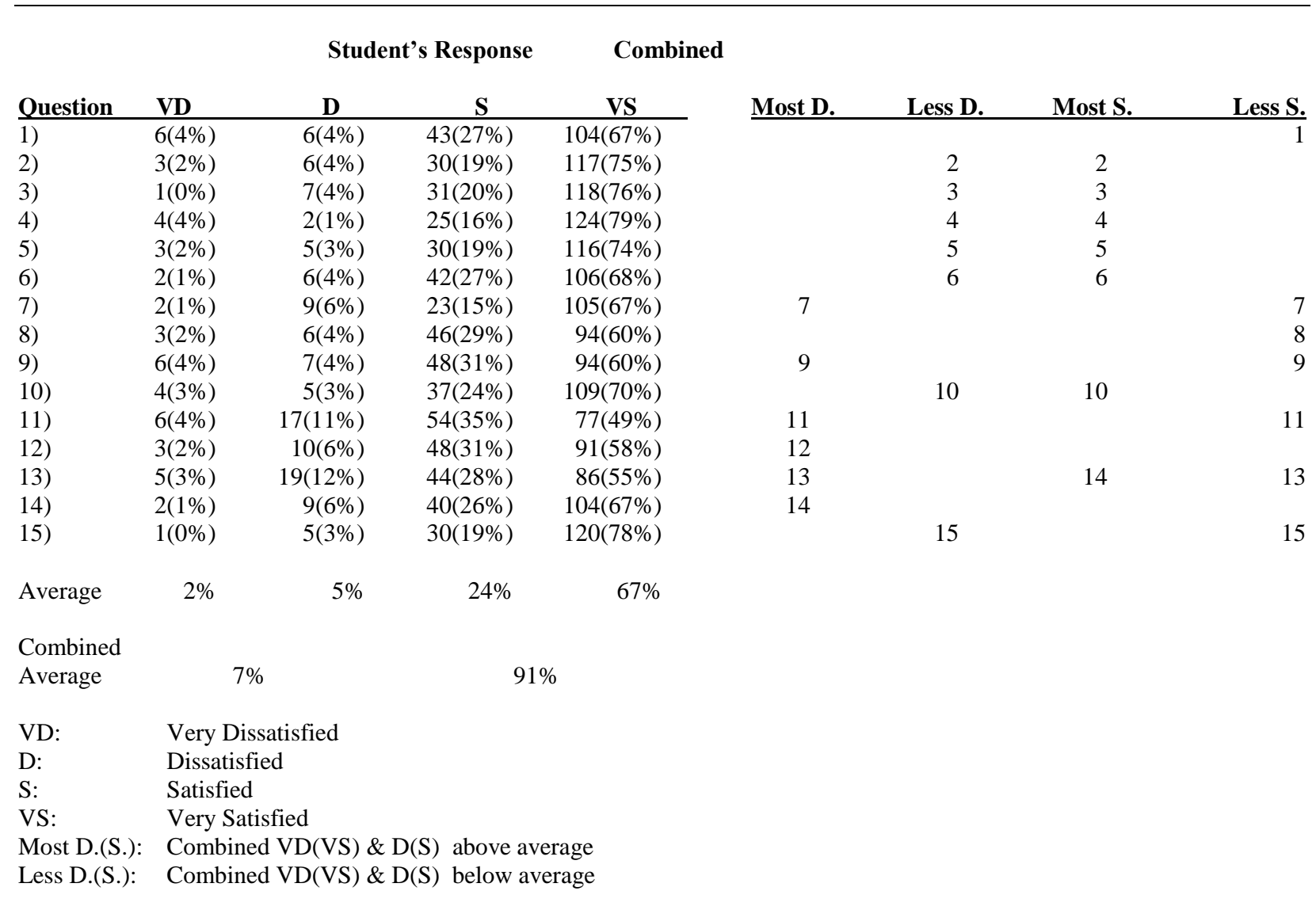

\section{AUTHOR INFORMATION}

Tahmoures A. Afshar, Ph.D., MBA.

Associate Professor of Finance

BA, Tehran University, Iran; MA, MBA, Ph.D., Indiana University

Tahmoures Afshar has more than 20 years experience as a university professor in the area of finance. In addition to teaching at Woodbury University, he has taught at Webster University, Ithaca College, and Morehead State University. He is an active participant in professional organizations and meetings and has been recognized for his contributions as reviewer, discussant and chair of sessions. He has numerous publications in the fields of Finance, Economics, and Pedagogy. His articles have been published in the Global Business and Economics Review, the Journal of Business and Economics Research, and the Journal of College Teaching and Learning. He has been awarded four times the "Best Paper Award" at the College Teaching \& Learning Conference and the International Business and Economics Research Conference from 2003 2008. Tahmoures Afshar has three years in a row been awarded "The Most Challenging Professor" Award by the Woodbury MBA Association.

\section{REFERENCES}

1. Backhus D.(1989). Centralized Intrusive Advising and Undergraduate Retention. NACADA Journal 9, pp.39-45

2. Borland, K.W., (2001-2002). Assessing Retention: Six Steps and Four Paradigms. Journal College Student Retention: Research, Theory \& Practice, (3 (4), 365-380 
3. Cashin, W. (1979). Presentation to the Third National Conference on Academic Advising. In C.M. Chando (Ed.), Proceedings of the Third Annual Conference on Academic Advising (pp. 89-92). Omaha, NE:

Kansas State University

4. Couch, Renee Chaffin (2004). Trends in Sophomore Students' Perception of Academic Advising Services at East Tennessee State University. Doctor of Education Dissertation

5. Creamer, D.S. (2000). Use of Theory in Academic Advising. In Gordon, V.N. Habley, W.R. and Associates, Academic Advising: A Comprehensive Handbook (pp. 18-34). San Francisco: Jossey Bass Publisher

6. Creamer, D.S. (2000). Use of Theory in Academic Advising. In Gordon, V.N. Habley, W.R. and Associates, Academic Advising: A Comprehensive Handbook (pp. 18-34). San Francisco: Jossey Bass Publisher

7. Crockett, D.S.(1978). Academic Advising: A cornerstone of student retention. In L. Noel (Ed.), Reducing the dropout rate, New Directions for Student Services,3,(pp.29-35). San Francisco: Jossey-Bass

8. Fielstein, Lynda (1989). Student Priorities for Academic Advising. Do They Want a Personal Relationship. NACADA Journal, 9(1), pp.33-38

9. Kelly, Karl N. and Lynch, Mary Jean (Spring 1991). Factors Student Use When Evaluating Advisors. NACADA Journal 7(2), pp.34-40

10. King, M.C.(1993). Academic Advising: Organizing \& Delivering Services for Student Success. New Directions for Community Colleges, No.82. San Francisco: Jossey-Bass Publisher

11. Lowe, Anna and Toney, Michael (2000). Academic Advising: Views of Givers and Takers, Baywood Publishing Co., Inc., pp.83-106

12. Mohr, J., Eiche, K. Sedlacek, W. (1998). So Close, Yet So Far.: Predictors of Attribution in College Seniors. Journal of College Student Development, Vol. 39, No. 4, July/August 1998, pp. 343-354

13. Ryan, Carol C. (Spring 1992), Advising as Teaching, NACADA Journal, Vol.12(1), pp.4-8

14. Stevenson, J., Buchanan, D., \& Sharpe, A. (2006-2007). Commentary: The Pivotal Role of the Faculty in Propelling Student Persistence and Progress Towards Degree Progress. Journal of College Student Retention. 8(22) pp. 141-148

15. Tinto, V.(1975). Dropouts from higher education: A theoretical synthesis of the recent literature. A Review of Educational Research, 45,89-125

16. Tinto,V.(1987). Leaving college. Chicago; University of Chicago Press

17. Tinto, V.(1993). Leaving college: Rethinking the cause and cures of student attrition ( $2^{\text {nd }}$ ed.). Chicago; University of Chicago Press

18. Welty, W.W. (July, August 1989). Discussion Method. Teaching; Change, pp. 41-49

19. Wilson, Steve B., Mason, Terry W. and Ewing, Michael J.M. (1997). Evaluating the Impact of Receiving University Based Counseling Services on Student Retention. Journal of Counseling Psychology, 44, 3, pp. 316-320 